\title{
Membrane separation and characterisation of lignin and its derived products obtained by a mild ethanol organosolv treatment of rice straw
}

\author{
Patrícia Moniz ${ }^{\mathrm{a}}$, Cláudia Serralheiro ${ }^{\mathrm{a}}$, Cristina T. Matos ${ }^{\mathrm{a}, 1}$, Carmen G. Boeriu ${ }^{\mathrm{b}, * *}$, \\ Augustinus E. Frissen ${ }^{\mathrm{b}}$, Luís C. Duarte ${ }^{\mathrm{a}}$, Luísa B. Roseiro ${ }^{\mathrm{a}}$, Helena Pereira ${ }^{\mathrm{c}}$, Florbela Carvalheiro ${ }^{\mathrm{a}, *}$

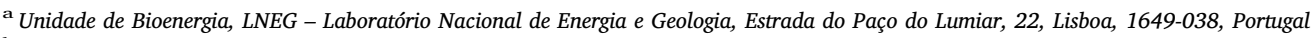 \\ ${ }^{\mathrm{b}}$ Wageningen Food and Biobased Research, Biobased Products, Bornse Weilanden 9, 6708 WG, Wageningen, The Netherlands \\ ${ }^{c}$ Centro de Estudos Florestais, Instituto Superior de Agronomia, Universidade de Lisboa, Tapada da Ajuda, 1349-017, Lisboa, Portugal
}

\section{A R T I C L E I N F O}

\section{Keywords:}

Combined pretreatment

Phenolic compounds

Added value compounds

Purification

Lignin

\begin{abstract}
A B S T R A C T
An organosolv process using ethanol-water was optimized in order to recover high quality lignin from rice-straw previously pre-treated by autohydrolysis at $210^{\circ} \mathrm{C}$. The results showed a selective and appreciable removal of lignin under very mild conditions and the highest delignification yield occurred at $30^{\circ} \mathrm{C}$. The lignin extracts were characterised using capillary zone electrophoresis (CZE), size exclusion chromatography (SEC), Fourier transform infrared spectroscopy (FT-IR) and ${ }^{31} \mathrm{P}-\mathrm{NMR}$, and two-dimensional heteronuclear single quantum correlation NMR spectroscopy (2D-HSQC NMR), which enabled the identification of low molecular weight lignins with a syringyl/guaiacyl ratio of about 0.74 containing phenolic compounds with potential bioactive properties.

In order to separate the target compounds, membrane technology has been used and an enriched extract containing value-added phenolic compounds such as tricin, vanillin, ferulic acid and p-coumaric acid was obtained. High membrane efficiency (around 80\%) was obtained for target compounds.
\end{abstract}

\section{Introduction}

Agricultural residues are considered interesting biomass feedstock for biorefineries due to their low cost and availability [1,2]. Their efficient utilisation within the biorefinery concept requires the selective fractionation of components to enable their separate exploitation for defined purposes [3]. Extensive research has been carried out for the separation of the three main structural components of biomass, hemicelluloses, cellulose and lignin, often in association with an initial removal of extractives [4].

In this framework, rice straw has been selectively fractionated by using a two-step process approach [5], namely, an hydrothermal treatment (autohydrolysis) is applied, by which most of the hemicelluloses are hydrolysed and can be recovered in the liquid phase as xylo-oligosaccharides and xylose, followed by a low intensity ethanol organosolv process to recover a liquid lignin fraction and a celluloseenriched solid phase [5].

Both qualitative and quantitative composition of the organosolv lignin-derived stream may be influence by several operational parameters, most noteworthy, temperature; hence, this must be carefully studied. Characteristically, these streams contain many phenolic compounds, some of which are known for their potential bioactivity, but prior to their utilisation, its separation and purification is required. Typically, organosolv lignins can be first isolated by evaporation and/or freeze-drying of the solvent, but these processes have the disadvantage that they are not selective $[4,6]$ and the recovered crude lignin must be further processed to obtain the relevant target compounds.

The application of membrane technology for processing the liquors from the delignification of a number of raw materials has been considered [7-9]. The use of ultrafiltration (UF) membranes, nanofiltration (NF) membranes or both has been applied mainly to remove non-lignin derived compounds from the extracts. For example, the combination of UF-NF was studied for the separation of hemicelluloses or other products, such as salts and monosaccharides, from black liquor [10,11]. The efficiency of various membranes for the fractionation and purification of hemicellulosic oligosaccharides was also demonstrated [11-13].

Membrane techniques can be particularly useful for the separation of lignin-derived compounds for added value applications such as

\footnotetext{
* Corresponding author.

*** Corresponding author.

E-mail addresses: Carmen.Boeriu@wur.nl (C.G. Boeriu), florbela.carvalheiro@lneg.pt (F. Carvalheiro).

${ }^{1}$ Current address: European Commission, Joint Research Centre (JRC), Institute for Environment and Sustainability (IES), Sustainability Assessment Unit, Via Fermi, 21021, Ispra, VA, Italy.
} 